\title{
Revitalizing Historic City Centers through an Integrated Approach: Arab City of Sanaa in Yemen.
}

\author{
Abbas A. F. Al-Warafi \\ Department of Architecture and Interior Design \\ University of Bahrain, Bahrain. \\ E-mail: alwarafi2002@gmail.com
}

\begin{abstract}
The rapid urbanization in the developing world has brought about insurmountable challenges to the inner historic quarters. With the population increase and improved economies, the middle class and the rich abandon the old quarters in preference for the wealthy suburbs while the poor find abandoned city core affordable. Historic inner cities thus become ghettos with their traditional owners fleeing the old buildings or actively destroying its very fabric by abandoning them to decay.

Old quarters provide the historical memories of the cities, their cultural base and a layer of the city identity. Their urban contexts are generally rich with a strong sense of place both the citizens and the countrymen cherish and would want to retain. Allowed to decay, such cities will lose a significant part of their identity. Thus, they must make concrete efforts to protect the historical urban contexts and revitalize the old quarters to ensure that their streets and spaces remain alive. This indeed requires their economic base rejuvenated and links to the surrounding modern cities reinforced. More than just restorations of few buildings, this is a herculean task of urban revitalization. To transform these urban quarters, it is necessary to create a powerful upward spiral of investments and rising incomes among their inhabitants as well as social engineering leading to social cohesion to restore the inherent vitality and unique charm of these city centres, by strategic interventions. If an integrated approach is taken, these regions can be made to flourish naturally.

This paper examines one such historic city center in the Arab region; Sana'a in Yemen, which has faced the dire consequences of urbanization. Although different geographical contexts may have their own issues, there are universal lessons to be learned from an in-depth study of the walled city of Sana'a as a typical Arab city. The study employs a case study approach, and through physical observations and documentary evidence, it constructs an integrated framework that considers the physical characters, socio-cultural realities, planning and development controls and economic processes. The paper divulges the inherent obstacles that prevail in Sana 'a and offers ways and means of overcoming these to transform them in particular and Arab cities in general. If done well, they may thrive as urban hubs they used to be, sustaining their populations and re-utilizing an enormous wealth of buildings, spaces, and systems that would otherwise perish under the pressure of urbanization.
\end{abstract}

Keywords: Historic Cities, Conservation, Revitalization, Sana'a, Integrated approach. 


\section{Introduction}

Pinheiro et al (1993) point out that urban development and planning schemes implemented to meet the emerging needs of the historical centers of cities should endeavor to manage the dichotomy of conservation and development to improve the social situation of such places. In conservation and urbanism, there is a theoretical dichotomy involving the traditional and the modern. On the one hand, some incline towards 'regionalism' and share a static thought of the traditional, as though the traditional areas could be protected from the real world and kept flawless. On the other hand, others point towards more interactive models for global developments, and acknowledge the pressures that emerge from economic and political forces. In this case, traditional is not necessarily opposed to modern as the terms comprise complementary parts of the same reality (Pinheiro et al;1993).

Until the 1940s, few countries considered the importance and values of the traditional cities. As a result, architectural heritage of significant buildings of public use were dealt with by applying the notions of preservation rather than conservation. However, as Fify (2014) says, they were dealt with in isolation from their traditional environments. It was the subsequent World War and the mass decimation of urban areas in Europe which led to rethinking of old urban areas. The re-building which happened over Western Europe during the 1950s and into the 1960s prompted more attention to the characters of these areas and the need to treat them delicately and productively. As Steinberg and Florian (1996) point out, there emerged analysis of the cutting-edge school of engineering and the 'bulldozer' school of arranging.

From these various experiences emerged the ideas of urban rehabilitation and revitalization. However, this means neither the mere protection of individual buildings of historical significance nor the preservation of everything old. Instead, it means the creative use and re-use of the old quarters of the cities (Teferra, 2016). Embaby (2014) points out that often, these included the upgrading of infrastructure services, but on a modest scale allowing the preservation of the existing urban pattern and fabric to take place.

From Europe, the ideas spread to the other parts of the globe including the Arab world, where large parts of historic quarters were being abandoned in preference to the modern developments promoted by new wealth. The old quarters were rich with the cultural heritage, yet were unable to provide the modern day comforts in terms of vehicular access, services and infrastructure. Moreover, the traditional construction technologies were hard to be implemented with the collapse of the skilled labour and workmanship mooted by western style education and training focused on more modern technologies.

The demise of the historic quarters of the city centres in the Arab Wolrd as same as everywhere else has suddenly led to the discovery of loss of cultural connectivity and anchorage of the communities. While in some places such as Dubai where the past has been completely eradicated, there are many not-so-rich Arabic cities which had allowed those decaying city centres to exist even if they were occupied by the poor or the migrant labourers, leading to further dilapidation and deterioration.

This issue is of course not new and many have examined hitorical city centres. Many have divulged chronic issues of dilapidation, poverty and degradatin of cultural memories. However, the intention of this paper is differnt. It is to advance a methodical model with strategic principles which can be applied to transform the revitalization of such historical Arabian city centers. 


\section{Historic City Centers of the Arab World}

Abudib (2016) points out that the historic centers of the Arab world generally continue to decline, with their physical, social and economic functions disrupted and potential contributions to the city's overall progress under-utilized. This is true of the cities of the rich Gulf states as well as those in other regions, such as North Africa and West Asia. However, much of the traditional, valued elements and characteristics of them still prevail albeit in dilapidated states of varying degrees. Moreover, the governments have come to realize the need for and the usefulnesss of revitalizing them, both for reinforcing cultural values that underpin their societies, as well to minimize huge economic burdens of rebuilding or newly building to accomodate those communities. In fact, there is a dire need to strike a balance between the requirements of rapid growth and the preservation of the authentic character of those centers and their unique cultural heritage. The cumulative impact of misplaced development practices of such cities driven by increasing populations can be listed as follows:

- Physical deterioration of their structures (buildings).

- Over-crowded marketing activities, which lack essential civic services.

- Rapid physical as well as functional transformations.

- Occupation by minorities and local migrants and workers.

In this regard, Kigadye (2014) draws attention to the following issues:

i) Economic:

It is inconceivable for any city administration to allocate sufficient budgets for rejuvenating an old city. Most likely, the earnings from tourism industry may be employed to renew the city and improve the income of inhabitants. However, it is also worth considering the use of the old markets and their structures for income related activities (Dix,1995).

ii) Social: It is perhaps not always possible to include communities during the process of rejuvenation and conservation of properties (Feilden et $\mathrm{al} ; 1998)$.

iii) Network:

The deterioration of the network and the infrastructure causes deterioration of living conditions in the old cities. It will be difficult to improve the system as an instrument for rejuvenation, but may be possible to rehabilitate and re-utilize open spaces to rejuvenate and enhance living conditions (Feilden and Jukka, 1998).

iv) Shells (buildings):

It is important to improve the condition of the old buildings employing both private and public engagements. In fact, it is feasible to rehabilitate, adapt, and re-use old structures for the present or futue use (Lamprakos, 2005).

v) Function:

The functions of old cities need to be stimulated to rejuvenate livable activities within their fabric and to improve the management of cities. Thus, it is viable to combine mix-uses even in the residential quarters. (Feilden et al;1998). 


\section{Conservation and Changes in the City: A Theoretical Basis}

Worldwide, there is a developing cognizance that city, town and village exist in time as well as in place. Their shapes and appearances are derived from their histories as well as present-day functions, which may change over time to meet new economic, social, or technological demands. The facilities have to meet the ever increasing day-to-day needs of the people. In every part of the world, historic sites are a reflection not only of wealth, climate, and materials but also of the changing circumstances of the society (Dix,1994).

Within these urban areas, increased densities and scales have changed the character of many historic cities, even where the plan remains the same albeit superficially. The most significant change - especially in the third world - has arisen as a direct consequence of urbanization and the growth of the cities (Dix,1994).

Conservation and upgrading of old towns and cities whatever their size cannot succeed based on purely architecture or engineering interventions. It is because good urban design is an activity requiring the consideration of all aspects of urban planning in a program that balances the new and the old.

As Lamprakos (2005) argues, it is - or would be-impossible to consider conservation of the old cities separately from the construction of the new. They are essential and complementary aspects of the development of settlements, because buildings and towns are parts of history, reflecting the likes and dislikes of people, fashions and technology, and periods of wealth and times of poverty. In fact, Lamprakos (2005) points out that there should be a policy to retain some buildings, or even parts of towns as milestones in the evolution of a city or state based on these aspects.

According to Lamprakos (2005), conservation is concerned with the wise and beneficial use of resources and buildings, roads and other structures as much as resources or raw materials found in the landscape. They represent an immense physical and financial investment and if obsolete, they can be used or adapted to meet the new needs. They also represent spiritual importance that transcends religion and helps to provide a source of stability and reassurance in a changing world. Indeed, conserving the notion or an artifact may create the feeling of security or satisfaction that gives people the feel of a town, a square or a street. Alternatively, one may ask if it is the substance of particular buildings, their forms, size, or color that we prefer to retain. One must ascertain if it is a satisfaction prompted by greenary or the presence or the absence of noise or other experiential aspects that make an old urban area sufficiently significant for people to desire to see it remain. However, Dawoud et.al, (2018) point out that whatever the basis, be it idea or artifact, emotion, aesthetic or economic, the case for conservation is now unquestionably accepted.

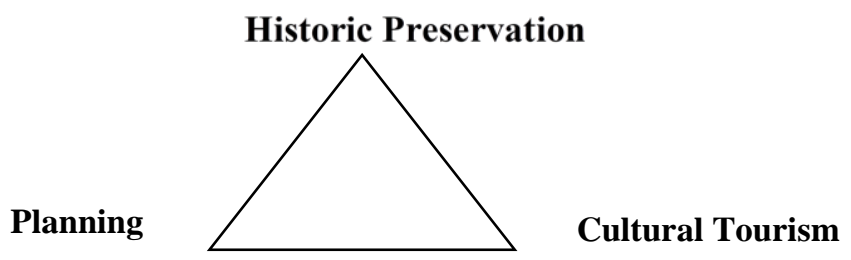

Fig 1: Conservation and Cultural Tourism Source: Author

Marcuse (1998) says that historic preservation, cultural tourism and planning stand in a triangular relationship to each other. None can be done without the other. As he says, if historic preservation is seen solely as a freezing of the past without regard to the life of the city around it or its economic impacts, it is unlikely to be meaningful preservation; indeed not even good economics.

If historic preservation is seen solely as a magnet to attract tourism and through its tourist dollars, it will also likewise be both not-so meaningful preservation and not-so good economics. Marcuse (1998) points out that preservation must reflect existing 
social, political, and economic relationships in ways which might indeed be pioneering in establishing a new meaning and role for both preservation and tourism. Alternatively, demo-tourism or tourism related to and based on respect for people, just as eco-tourism "is related to and based on respect for the environment" (Feilden et al;1998) might provide an approach to meeting the sometimes-conflicting need for historic preservation and economic development

With history throughout times, and with history throughout space, historical centers need a delicate balance. As Marans (2015) point out, first, through historic centres, all the histories of all peoples' lives, and the reflection of those lives in the built environment need to be shown. That requires first, interpretation rather than demo lition. Second, the history of a city is not limited to one area of its centre. Within this space, there were changes. The conservation of history does not mean the freezing of these changes and activities.

\section{What is to be Conserved and Revitalized?}

If the case for conservation is made, we should recognize what is to be conserved, on what basis, and at what cost. In every case, buildings, spaces (internal and external) and plantations (landscapes) will be involved, but if the fundamental situation is with the persona of the vicinity and the activities involved, structures turn out to be less critical, or perhaps even obsolete (Lepelaas, 1996;Veldpaus et al, 2013).

For instance, if the hustle and bustle of people and traffic in a busy city core is the situation of conservation, ancient buildings should possibly be changed or renewed sensitively without being detrimental to the activities or the atmosphere, while maintaining the character (Lepelaas, 1996; Veldpaus et al, 2013).

Feilden et al (1998) argue that attention must be focused on the urban ensemble rather than the architectural merit of individual buildings and on any new uses such as those that are at least in general accord with those traditionally present. Activities are essential for them to change the uses for which a building or piazza is put. They can enhance or destroy its character, and may therefore, be desirable to protect in some way the structure and use of both the buildings and spaces. The objectives and criteria must be agreed upon before any positive conservation can be achieved (Steinberg,1996; Haidar et al, 2013). Historic centres can still continue to be the centre of life and work for the people, but whether or not they can do so depends to a large extent on whether the interventions carried out in them are not against what has already been achieved in terms of preservation and do contribute to a socio-economic improvement of the area as a means of guaranteeing that their populations can continue to work. At the same time, rationalization in the use of open spaces in the historic centres must be sought in relation to the development of the whole city. Integration in the wider context will allow the historic centres to contribute to the character and historic richness to the whole city.

\section{Research Methodology}

The methodology adopted for this paper endeavors to develop an understanding of 'revitalization concepts' as a 'special form of planning' and emphasizes both aspects; the 'comprehensiveness of different approaches' for dealing with the existing traditional environments, and its 'accommodation for change and continuity of use' in the contemporary society.

The investigation adopted the following steps: 
A) Examining and revieweing documentations dealing with different revitalization approaches applied to a city centre of historical importance has been of immense value. The review pertains to the relevant research undertaken in the past by international institutions as well as individual professionals. The review has been undertaken to analyse the natural sequence of revitalization approaches applied to ancient areas or conglomerations in a chronological order. It is the general observation that, to some extent, there are similarities in the nature of the problems of the older urban areas in a city, irrespective of whether it is in a developed country or in a developing country. Though most of the literature reviewed relates to western countries, it is a very important source to learn not only from successes (or partial successes) but also from the failures of different approaches. Documentary review is an important aspect in this research because most of the research work in the area of town planning and urban design depends on acquired knowledge and experience gained over several generations. Therefore, documented information is an important source of data.

B) Data collection: Data have been collected from various references, published books, and reports and articles related to revitalization of historic towns and cities, in general and from the literature and documentation related to the walled city of Sana'a or the traditional Arabian cities, in particular.

C) Evaluation and review of the situation of walled city of Sana'a from different angles followed by correlation of the different factors.

\section{Research Findings:}

\subsection{The Background: Walled city of Sana'a}

Sana'a is the prestigious capital of 'Arabia Felix' and is regarded as one of the oldest cities in the world. The city dates back to the First Century A.D. Sana'a lies in the geography of Arabian peninsula. It is the capital of the Republic of Yemen.

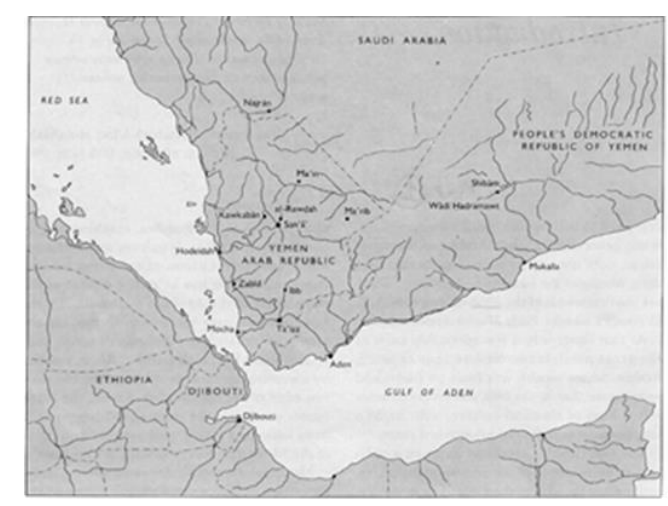

Fig. 1: Map of Yemen. Source: 
The area of the walled city of Sana'a is 130 hectares as a cross-area, constituting $67.3 \%$ of the area for buildings, $17 \%$ open space as a major feature of the old city, $9 \%$ roads, $7.3 \%$ central souq, $2.2 \%$ for traditional public service and $0.8 \%$ for other public services (Creighton, 2007).

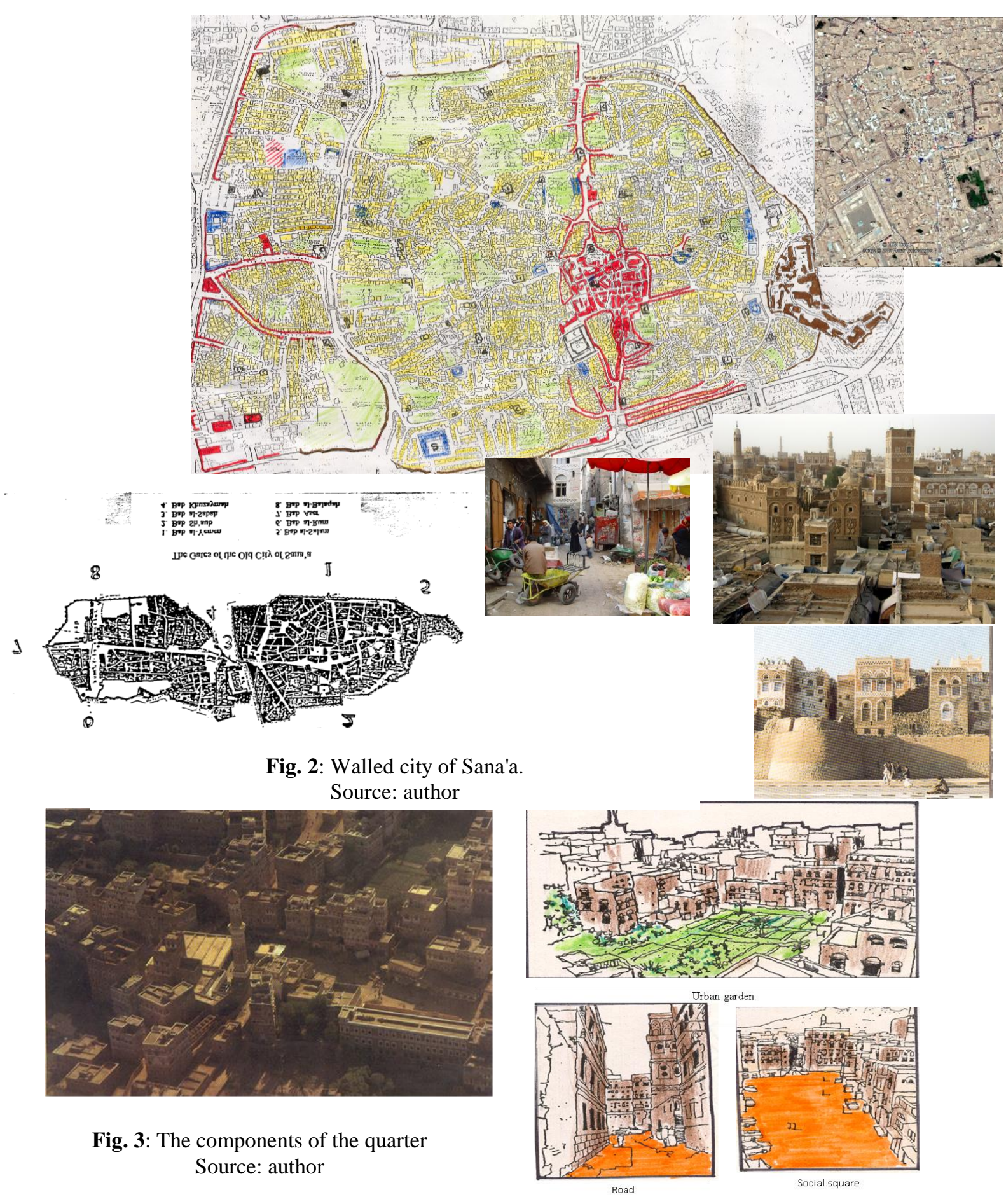

Fig. 4:The urban space of old Sana'a. Source: author 
Table 1: Land use 2014

\begin{tabular}{|ll|c|c|}
\hline Land use & $\begin{array}{c}\text { Area in } \\
\text { hectares }\end{array}$ & $\begin{array}{c}\% \text { of total } \\
\text { area }\end{array}$ \\
\hline - & Residential & 87.10 & 67.0 \\
- & Open space & 24.80 & 19.0 \\
- & Road "Access" & 11.70 & 09.0 \\
- & Central suq. & 04.81 & 03.7 \\
\hline
\end{tabular}

Source: Sana'a report to UNESCO

Table 2: Acceptable standards in critical area

\begin{tabular}{|c|c|c|}
\hline Factors & $\begin{array}{c}\text { Acceptable standards in } \\
\text { critical factors }\end{array}$ & $\begin{array}{c}\text { overall target for old } \\
\text { city }\end{array}$ \\
\hline Density & $550 \mathrm{p} / \mathrm{h}$ maximum & $300 \mathrm{p} / \mathrm{h}$ \\
\hline Site coverage & $50 \%$ max. & $40 \%$ \\
\hline Road "Access" & $12 \%$ Minimum & $15 \%$ \\
\hline
\end{tabular}

Source: Sana'a report to UNESCO

The city is composed of many quarters; normally identified after the largest mosque of the quarter. The housing cluster represents a primary unit of the city's morphology and has its own characteristics and social structure. A particularly important attribute of the housing cluster is that it consists of four elements in unique arrangements; the houses, the urban garden, the social square and the roads. The Souq (the market) of Sana'a has played a dominant role in the history of Sana'a and is the geographical element in the whole until today ${ }^{1}$. The market of Sana'a is a single-story area located in the heart of the modern city (Ministry of Culture and Tourism, 1999)

Samsarah is a particularly Yemeni term for the building of commercial mediations, deposits, stores or warehouses, for storages of merchandise, commercial transactions, combined with hostelry function for a brief stay of travelers, traders, merchants, and even their animals. The terms 'Khan', 'Funduq' or 'Caravanserai' describe buildings of a similar type but do not cover the full meaning of 'Samsarah'. These buildings are related to the market and constitute the most famous buildings and institutions of the markets, controlling the inflowing trade, accommodating the trade caravans, storing the merchandise and redistributing them in the market area (Ministry of Culture and Tourism, 1999).

The houses (represents the main physical component of the city (Shell in Table 1) are divided into one apartment per floor, and they may receive little maintenance. In fact, many houses have been abandoned, mostly due to problems of inheritance. Many have also turned into rental units providing accommodation to the poor workers. When repairs are due for such buildings, the materials and methods are sometimes not the same as the traditional ones; most building violations in the old city concern additions, repairs or changes made with the new materials. According to Lewcock (1998), there are also complete building destructions making way for new structures; usurping of public gardens for new private construction and additions made to existing buildings that are foreign to the mass, scale, volume, and materials of the built heritage.

Traditionally, open spaces, in the walled city of Sana'a, such as squares and gardens were well-used. The gardens (Basateen and Magashim) were the lungs of the city and provided visual relief. The urban gardens are mostly the property of Waqf foundations and support the local mosques. An urban garden usually constituted between $35 \%-45 \%$ of the whole of the housing

\footnotetext{
${ }^{1}$ A survey in the years 1971/72/74 counted 1680 shops; workshops and service - enterprises in the market of Sana'a altogether
} 
cluster area, whatever the size of the housing cluster, and it works in connection with the system of wells and mosque ablution system (Ministry of Culture and Tourism, 1999).

The social square is a traditional feature of the area where people gather on different occasions, such as feasts, wedding parties, funerals and after Friday prayers. It is also a play area for children, and represents one of the valued areas of social life. Social square is not in use any more as intentded due to change of the urban lifestyles, as the social activities occur inside the houses or outside the walled city. Moreover, as Creighton (2007) points out, the squares subjected to different factors have led to a reduction of its traditional functions. The new requirements of residents have led to the use of the squares for numerous other activities.

Generally, the prime functional and physical problems of walled city of Sana'a is that of overcrowding and congestion which includes too many buildings and too much traffic on too small an area of land. Physically, it suffered gradual renovation in construction and change in land use and deterioration in services. The worn-out and obsolescent buildings result in destruction by abrupt and violent social and technological change. Walled city of Sana'a as a city center has faced many challenges like population growth, the influx of migrants, evolving economic base, continued consumption of historic assets, and the destruction caused by tourism.

The decreasing purchasing power has led to a gradual transformation of old Sana'a as the opening of shops on the ground floor of a steadily increasing number of small and medium-sized houses. When a commercial activity is not yet profitable, these shops are rented to rural and provincial newcomers; including peddlers, petty traders and retailers in the market. The low income of house owners works as an additional incentive for migrants to find accommodation close to the areas where they work.

Table 3: Ownership of Buildings

\begin{tabular}{|c|l|}
\hline \multicolumn{2}{|c|}{ Ownership of Building } \\
\hline $76 \%$ & Owning \\
$20 \%$ & Lease \\
$4 \%$ & Owning and lease \\
\hline
\end{tabular}

Source: Survey July-August, 2014

\subsection{Aspects Related to Conservation and Revitalization}

Realistically, no one argues for the total renovation of everything historic in a city. Equally, few would quarrel with attempts to improve infrastructure and services, reduce overcrowding, or otherwise improve the dwelling situation in older areas. Such enhancements do provide a better living environment. However, a better surrounding also implies a pleasing combination of social and cultural lifestyles for those who make use of the environment and resources. It is the human inhabitants who create and constitute the social, cultural and economic systems which provide lifestyles to the physical environment or function of the area (Steinberg, 1996).

The focus of revitalization and conservation of historical centers, therefore, must be on whole areas, not just individual buildings and social communities, or just the built environment. (Fister, 2001) The real focus should be on the function; 'the Activities and use of buildings' taken, and the need to upgrade selectively and adaptively. Thus, the general focus on the inhabitant and the aspects which affected the settlements as mentioned in the framework are applied to the case of Sana'a as follows.

\subsubsection{Economic Aspects:}

Even if urban revitalization and conservation is not an unprofitable activity, in most countries, there is no mechanism for financing revitalization projects and therefore extra efforts will have to be put in, in order to develop and test the financial modalities. Mixing public and private resources will probably be an essential element of successful approaches (Jakarta \& Steinberg, 2005) The fact of revitalization raises the question if and how new/old uses, rising land prices and taxes and possible revenue and other 
effects from tourism can be utilized for revitalization, instead of letting new developments get the better of the historic areas. The contribution of the older areas to the economy has been consolidated through retaining and even enhancing their historical value.(Jakarta, \& Steinberg, 2005)

The main source of funding for investment of such projects has been the small-scale bilateral grants from a large variety of donors. Most of these projects require some counterpart funds (matching shares) generally between $10 \%$ and $50 \%$ from the Yemeni government apart from operation and maintenance part which has to be taken care of by the Yemeni government. The investment of funds will be approved by the Ministry of Planning and Development (MPD) and be placed (generally annually) in a special fund in the Central Bank of Yemen. Operation and maintenance and other current finances do not generally come under the (MPD) but the Ministry of Finance (MoF).

Table 4: The Change and Willingness for Maintenance and Change

\begin{tabular}{|c|c|c|c|c|c|c|c|c|c|c|}
\hline Area of focus & Façade & Floor & Walls & Roofing & Fitting & $\begin{array}{c}\text { Tilling } \\
\text { /plaster }\end{array}$ & Color & Opening & $\begin{array}{c}\text { Stair } \\
\text { case }\end{array}$ & $\begin{array}{c}\text { New } \\
\text { const. } \\
\text { additional }\end{array}$ \\
\hline $\begin{array}{c}\text { Maintained } \\
\text { with changed }\end{array}$ & $38 \%$ & $28 \%$ & $32 \%$ & $56 \%$ & $40 \%$ & $28 \%$ & $20 \%$ & $16 \%$ & $24 \%$ & $16 \%$ \\
\hline $\begin{array}{c}\text { Willing/ } \\
\text { Wishing for } \\
\text { change }\end{array}$ & $28 \%$ & $28 \%$ & $40 \%$ & $32 \%$ & $16 \%$ & $32 \%$ & $24 \%$ & $20 \%$ & $20 \%$ & $36 \%$ \\
\hline
\end{tabular}

Source: Survey July-August , 2014

To that end, urban managers, planners, and heritage conservationists in the walled city of Sana'a should take into account in their practice a number of aspects.

They should consider the following questions:

- How can urban revitalization/conservation be financed?

- How much mix of private and public resources, public-private partnerships, should be used?

- How can older land use and activities co-exist with new ones?

- What happens when land values and/or taxes increase?

- How can the contribution of the older area of the urban economy be consolidated?

- Which economic role could tourism play in this context?

Table 5:Willing/ability for maintenance

\begin{tabular}{|c|c|c|c|}
\hline $\begin{array}{c}\text { Willing/able to } \\
\text { maintain }\end{array}$ & Willing & Able to do partly - completely & Together \\
\hline Yes & $34.4 \%$ & $28.2 \%$ & $37.6 \%$ \\
\hline No & $65.6 \%$ & $62.4 \%$ & $62.4 \%$ \\
\hline Total & $100 \%$ & & $100 \%$ \\
\hline
\end{tabular}

\subsubsection{Social Aspects:}

A significant question is how the historic housing areas can upgrade, without raising property values leading to the development out of reach to the present, usually low-income population. In some cases, relocation may be unavoidable. In either case, the participation of the residents in the development is necessary. Hassan, de Trafford \& Youssef;2008). 
One of the aspects threatening the old city of Sana'a is the speed of modernization, which leads to social transformation with new requirements of new styles of life. It also coincides with the economically pulling zone around the city. As a result, more and more old families are building new houses and moving to their new outlying districts. Other important factors are the attractions of nearby educational facilities and medical health services.

Table 6: Sharing the house

\begin{tabular}{|c|c|}
\hline Percentage & $\mathbf{H} / \mathbf{H}$ \\
\hline $55.2 \%$ & Living alone \\
\hline $23.4 \%$ & $\begin{array}{c}\text { Living with another } \\
\mathrm{H} / \mathrm{H}\end{array}$ \\
\hline $21.4 \%$ & $\begin{array}{c}\text { Living together } \\
\text { with two and more } \\
\text { other } \mathrm{H} / \mathrm{Hs}\end{array}$ \\
\hline
\end{tabular}

Source: Survey July-August, 2014

Table 7: Willing/ability for maintenance

\begin{tabular}{|c|c|c|c|c|c|}
\hline $\begin{array}{c}\text { Willing/able } \\
\text { to maintain }\end{array}$ & Willing & $\begin{array}{c}\text { Able to } \\
\text { do }\end{array}$ & partly & completely & Together \\
\hline Yes & $34.4 \%$ & $28.2 \%$ & & $9.4 \%$ & $37.6 \%$ \\
\hline No & $65.6 \%$ & & $62.4 \%$ & & $62.4 \%$ \\
\hline Total & $100 \%$ & & & & $100 \%$ \\
\hline
\end{tabular}

Source: Survey July-August, 2014

In case of the walled city of Sana'a, the following questions should be considered:

- How can the poor, who generally comprise a majority of those living in the historic housing area, participate effectively in the revitalization process?

- How can the community of low-income residents be retained in the face of changing land uses and values? (or how can they be supported when relocation is unavoidable?)

- How can low-income residents be protected from the impact of 'gentrification'?

\subsubsection{Political and Urban Governance:}

One significant factor in revitalization and conservation is the generation of political support. Without support from authorities, the protection of the historic fabric will be extraordinarily difficult. Policies should be adopted to support the revitalization of heritage and integrate this with development strategies (Hardoy, and Gutman,1991).

The following questions should be considered:

- How can political support be generated and maintained?

- How can national policy in support of revitalization and conservation of urban heritage be established?

- How can the affected population participate in the formulation and execution of revitalization and conservation schemes?

- How can the institution and governmental and none-governmental organizations effectively play a significant role in the process? 


\subsubsection{Network Aspects:}

It is vital for revitalization to elevate the quality of city life and health of traditional contexts and to create a livable environment for users, inhabitants, visitors, and tourists and it is a tool to reduce the decline in the buildings and primary services. (Pinheiro et al,1993).

Table 8: Satisfied with Services

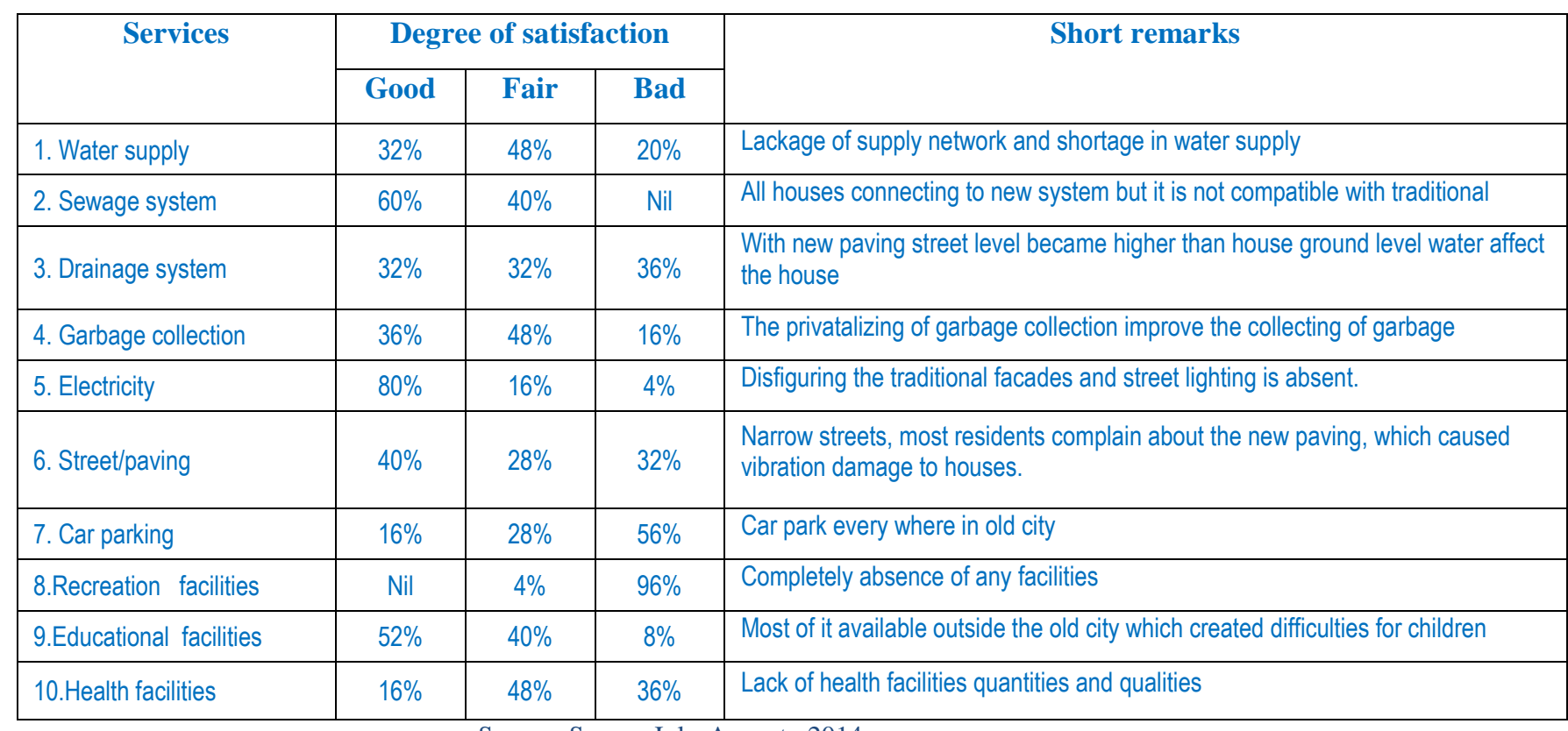

The following questions should be considered:

- How cantransportation issues be solved?

- How can preservation and revitalization tackle the public utilities?

- What role can recreation and entertainment play in the lives of inhabitants?

\subsubsection{Building Aspects (shells):}

One reason to conserve historic buildings 'shells' is the hope that this may strengthen indigenous culture and traditional forms and thus will add a sense of belonging among inhabitants and other users. The economic activities that are essential for urban prosperity can be encouraged by constructing new buildings appropriate for a new uses. However, if they do not interfere with historic environments, they can still accommodate new uses that are appropriate to the scale, size, and structural strength of old buildings and to carry capacity of roads. ( Dimelli, 2019).

The following questions should be considered for the walled city of Sana'a :

- To what extent can the revitalization of historic shells or buildings contribute to the strengthening of indigenous cultural traditions and form?

- What is the role of historic buildings, their physical characters, and their social life in the local (or national) culture?

- Can historic buildingslareas become an area of particular tourist interest? 


\subsubsection{Functional Aspects:}

Revitalization as a process may affect the function of the buildings, and the general function of the city or town (Yee Sing and Yoh; 2016). It should consider the following questions:

- How can the urban pattern and tissues of historical city area be preserved in the face of necessary upgrading and land-use changes?

- Can the historic quality of the mixed-use environment be adapted to present-day conditions?

- Also, how can that affect the function of the historic centers?

\section{The General Model}

To analyze the above questions, a revitalization framework has been developed to set these as mutual relationships between all the needed factors related to a historical town or fundamental elements of historical settlements (See Fig. 5)

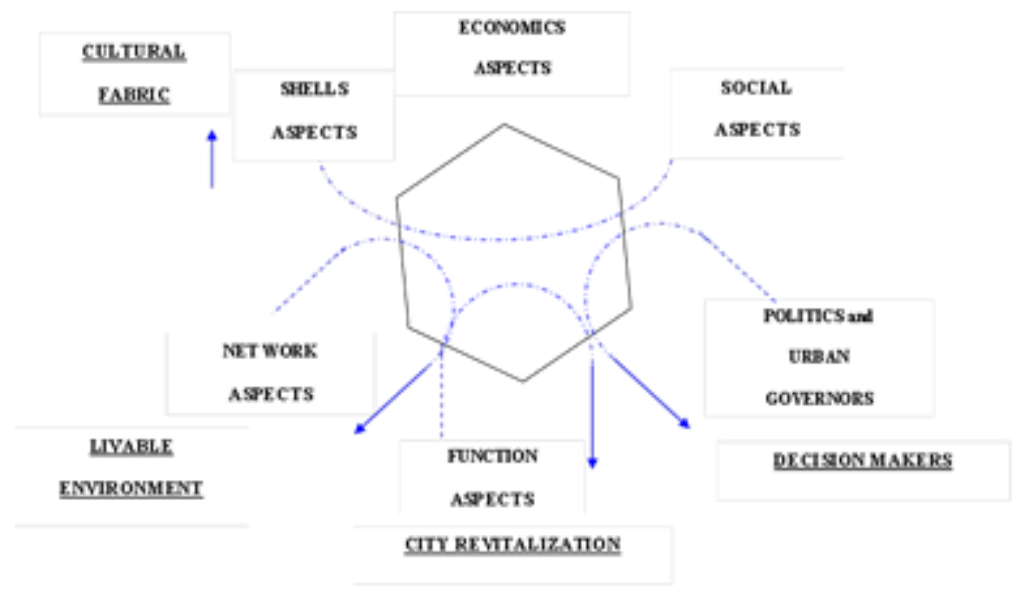

Fig. 5: Revitalization Framework

Source: Author

It is argued that every component of the framework ought to be mutually analyzed and correlated with other aspects. It will be extraordinarily useful in the following stages: (see Fig. 6)

- $\quad$ Evaluating existing situations.

- Analyzing and evaluating the problems.

- Formulating the strategies and recommendations as

Feasibilities and Opportunities.

Possibilities and Constraints.

These conceptualizations of the relationships between humanity and the urban elements of the environment relate well to the often-hidden rationales for urban conservation and revitalization. 
Inputs Factors

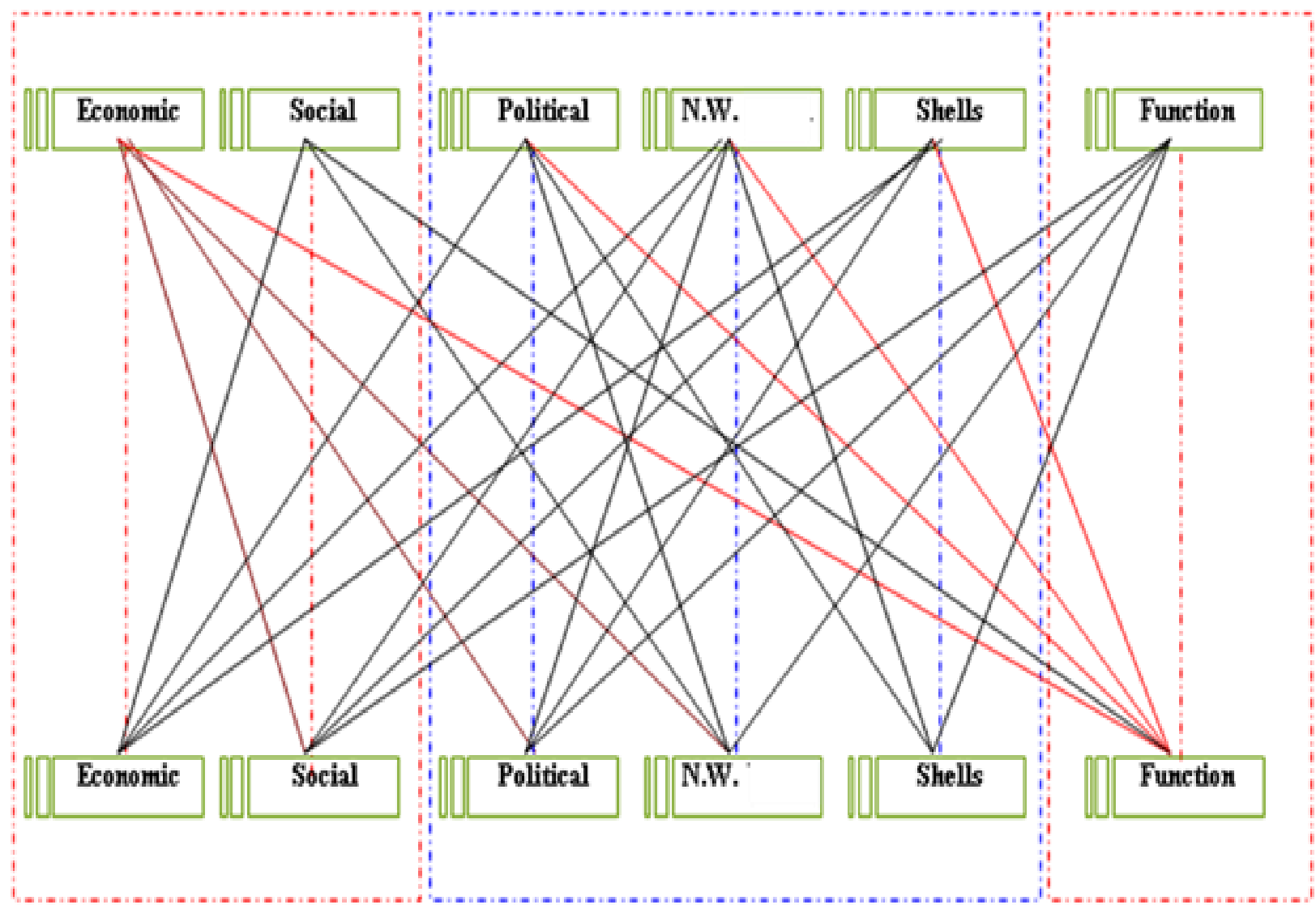

Out Puts Factors

Fig. 6: Inputs and Outputs Factors

Source: Author

\section{Conclusions}

The historical walled city of Sana'a suffers a gradual deterioration, renovation in construction and change in land use, increased traffic congestion, and deterioration in services, which leads to the general impoverishment of resident population and deterioration in the quality of life.

It is the general observation that, to some extent, there are similarities in the cause and nature of the issues of the older urban areas in Arabian cities with those of Sana'a.

To address the problems related directly to the walled city of Sana'a, we need a framework that brings together different actors. We need not have only sound finance and economics, but also an active political process that brings all actors together to undertake an effective approach to revitalize the old cities.

We will solve none of today's problems if we concentrate on isolated relations, such as between (1) Man and nature (2) Man and buildings, (3) Man and networks, (4) Man and society. All our mistakes can be attributed to just such isolations of relationships. 
To achieve a balance, we must systematically approach all problems, avoiding partial views of elements or specific goals. Our only road is continuing to create order out of the chaos around us.

The historic centers in the Arabian world demonstrate both the best and worst of contemporary developments. It also represents achievement and an immense investment of resources and experience in approaching individual aspects related to conservation, rehabilitation, and reuse.

Revitalization is concerned with the future of historic areas and involves selecting possibilities from the arrangement of various aspects that will most benefit the most considerable number of people and contribute to their welfare and the improvement of environment and economic activities.

The effectiveness of any intervention in historical centers depend on the mutual relationships and integration of the different aspects of revitalization; mainly, economic, social, political, shells (physical structure), network, and services. This paper proposed a model and recommended crucial questions related to the main aspects of revitalization devoted to the provision of a livable environment and economic activities. It also allows formulating a hypothesis to conduct further research in the area of conservation and revitalization of historic centers.

\section{References:}

Al-Kubaisy, F. S. (1987). “Conservation in The Process of Urban Renewal for Najaf Old TownIraq" Ph.D. Thesis, University of Roorkee,

Bernard M. Feilden And Jukka J. (1998). Management Guidelines for World Cultural Heritage Sites. Iccrom Second Edition Rome, Ograro 1998.

Creighton, O. (2007). Contested Townscapes: The Walled City As World Heritage. World Archaeology, 39(3), 339-354. Retrieved From Http://Www.Jstor.Org/Stable/40026204

Dawoud, Maher \& Elgizawy, Ebtesam. (2018). The correlation between art and architecture to promote social interaction in public space. 10.1201/9781315166551-9.

Dimelli, D. (2019) Modern Conservation Principles and Their Application in Mediterranean Historic Centers-The Case of Valletta. Heritage 2, 787-796..

Dix, G. (1994) Character, Conservation and Change: The Place of Preservation in The City. Ekistics, 61(368/369), 261-275.

Dix, G. B. (1995) "The Re-Use of Buildings in Historic Town : A Coincidence of Economic and Cultural Activities," Ekistics, Vol. 62, No 373/375, July-December.

Fabian S. K. (2014). Architectural Conservation in Rapidly Urbanising Cities: The Case of Dar Es. Publisher IFRA - InstitutFrançais de Recherche en Afrique. Electronic version Retrieved From http://journals.openedition.org/eastafrica/342.

Fekri Hassan, Aloisia De Trafford, Mohsen Youssef (2008).Cultural Heritage and Development in The Arab World. Dar El-Kuttub Depository No 22932/2008 Bibliotheca Alexandrina Cataloging-In-Publication Data

Fify, A. (2014). Sustainable Improvement and Management for Deteriorated Urban Area in Developing Countries. World SB14 Barcelona Conference. 28/30(2014). In Wsb14Barcelona.Org (pp. 110). Retrieved from http://wsb14barcelona.org/programme/pdf_poster/P-212.pdf.

Fister, P. (2001). Urban Rehabilitation - A Borrowed Novelty. UrbaniIzziv, 12(1), 117-122. Retrieved From Http://Www.Jstor.Org/Stable/44180355.

Haidar, L.A., Talib, A., 2013. Adaptive Reuse in The Traditional Neighbourhood Of the Old City Sana'a -Yemen. Procedia - Social and Behavioral Sciences 105, 811-822.

Hardoy, J.E. And Gutman, M. ( 1991 ) The Role of Municipal Government in The Protection of Historic Centers in Latin American Cities, Environment and Urbanization, Vol. 3, No. 1 April.

Huyam H. A. (2016). Exploring Contextual Characteristics of Traditional Medinas in North Africa. April 2016 International Journal of Architectural Research 10(1):325-343

Jakarta, H., Steinberg, M.F. (2005) Revitalization of Historic Inner-City Areas in Asia Urban Renewal Potentials In 836-848.

Lamprakos, M. (2005). Rethinking Cultural Heritage: Lessons from Sana'a, Yemen. Traditional Dwellings And Settlements Review, 16(2), 17-37. Retrieved From Http://Www.Jstor.Org/Stable/41747744. 
Lepelaas, F. (1996) Conservation and Rehabilitation of Urban Heritage in Developing Countries, Habitat International, Vol. 20, No (3),

Lewcock, R. (1989)., "The Campaign to Preserve the Old City of Sana'a,” Unesco, Report No. 5, Paris.

Marans, R.W. (2015. Quality of Urban Life \& Environmental Sustainability Studies: Future Linkage Opportunities. Habitat International 45, 47-52.

Marcuse, P.(1998 ) Historic Preservation, Cultural Tourism and Planning, Trialog 58/1998.

Ministry of Culture and Tourism. 1999 "Cultural Heritage (Protection) Project : Strategic Planning and Policy Framework," Vol.1 And Vol.2 Gilmore Hankey Kirke Ltd.

Mohga E. E. (2014) Sustainable Urban Rehabilitation of Historic Markets "Comparative Analysis", International Journal of Engineering Research \& Technology, Volume 03, Issue 04.

Pinheiro, A., \& Del Rio, V. (1993) Cultural Corridor: A Preservation District in Downtown Rio De Janeiro, Brazil. Traditional Dwellings and Settlements Review, 4(2), 51-64.

Serageldin, I. (1997) Our Past Is Our Future: Investing In Our Cultural Heritage [Www Document]. Url Http://Www.Serageldin.Com/Speech/Details.Aspx?Id=36

Serageldin, I. (1997) Solving the Rubik's Cube: Cultural Heritage in Cities of The Developing World, The Urban Age. Vol. 4.

Steinberg, F. (1997)The Situation of Old Housing Stock and Historic Centers: Rehabilitation of Inner-City Slums, Ish, News, Vol. 12, September 1997.

Steinberg, F. (1996) Conservation and Rehabilitation of Urban Heritage in Developing Countries. Habitat International 20, 463-475.

Teferra, Z. (2016) Urban Renewal and The Predicaments of Heritage Conservation in Addis Ababa, Ethiopia / RenouvellementUrbain Et Situations Délicates De La Conservation Du Patrimoine À Addis-Abeba, Éthiopie. In: AnnalesD'ethiopie. Volume 31, Année 2016. Pp. 107-132.

Veldpaus, L., Pereira Roders, A.R., Colenbrander, B.J.F., 2013. Urban Heritage: Putting the Past into The Future. The Historic Environment: Policy \& Practice 4, 3-18.

Yee Sing, T., Yoh, S., 2016. Rehabilitation Methods and Revitalization Strategies in The Old Inner-City Areas of Rapid Growth Cities in Asia. Urban and Regional Planning Review 3, 120. Doi:10.14398/Urpr.3.1. 